Marquette University

e-Publications@Marquette

College of Nursing Faculty Research and

Publications

Nursing, College of

4-2013

\title{
A Retrospective Review of Sliding Scale vs. Basal/Bolus Insulin Protocols
}

Heidi L. Rymaszewski

Susan Breakwell

Follow this and additional works at: https://epublications.marquette.edu/nursing_fac

Part of the Nursing Commons 
Marquette University

e-Publications@Marquette

\section{Nursing Faculty Research and Publications/College of Nursing}

This paper is NOT THE PUBLISHED VERSION; but the author's final, peer-reviewed manuscript. The published version may be accessed by following the link in the citation below.

The Journal for Nurse Practitioners, Vol. 9, No. 4 (April 2013): 214-218. DOI. This article is (C) Elsevier and permission has been granted for this version to appear in e-Publications@Marquette. Elsevier does not grant permission for this article to be further copied/distributed or hosted elsewhere without the express permission from Elsevier.

\section{A Retrospective Review of Sliding Scale vs. Basal/Bolus Insulin Protocols}

Heidi L. Rymaszewski

Aurora Medical Group-Diabetes and Nutrition Education Department, Milwaukee, WI

Susan Breakwell

College of Nursing, Marquette University, Milwaukee, WI

\section{Abstract \\ Purpose}

The purpose was to assess the differences between subcutaneous basal/bolus and sliding scale insulin protocols in patients admitted with type 2 diabetes on non-critical care units.

\section{Methods}

A retrospective review of electronic medical records was conducted on a convenience sample of inpatients in a central-city teaching hospital. 


\section{Results}

The findings were that basal/bolus protocols achieved American Diabetes Association glycemic targets on fasting, mean, and discharge blood glucoses.

\section{Conclusions}

This study provided insight into glycemic control and interdisciplinary education needs at this hospital. Evidence revealed that basal/bolus insulin protocols can achieve glycemic targets.

\section{Keywords}

basal/bolus insulin protocol, sliding scale insulin protocol

Hyperglycemia, or high blood glucose, among hospitalized patients is associated with adverse shortand long-term outcomes such as increased lengths of stay and increased time for healing. In fact, in 1 study, ${ }^{1}$ the association of hyperglycemia and mortality was greater in patients without a history of diabetes compared to those with diabetes. A retrospective analysis determined that nearly $25 \%$ of patients admitted with diabetes were hyperglycemic, with a blood glucose $>200 \mathrm{mg} / \mathrm{dl}(11.1 \mathrm{mmol} / \mathrm{l})$ upon admission because they were either poorly controlled on their prehospital diabetes regimen, or they were poorly controlled because of their primary admission diagnosis, which often was related to infection. $^{2}$

For the majority of nonacute hospitalized patients with diabetes, pre-meal blood glucose targets should generally be $<140 \mathrm{mg} / \mathrm{dl}(7.8 \mathrm{mmol} / \mathrm{l})$, with random blood glucose levels $<180 \mathrm{mg} / \mathrm{dl}$ (10.0 $\mathrm{mmol} / \mathrm{l})$. Special considerations need to be taken into account, however, for patients with severe comorbidities and those who are terminally ill when higher glucose targets may be warranted. ${ }^{3}$

Subcutaneous insulin therapy is the preferred method of glycemic control on non-critical care units for patients with diabetes. There are various types of insulin protocols for treating hyperglycemia in the hospital setting. Treatment options include sliding-scale insulin or basal/bolus insulin therapy. Hospitalized patients are prone to large variances in blood glucoses. Because of this, effective treatment is required to maintain satisfactory, safe glucose control. Subcutaneous sliding-scale insulin has been long-used as routine therapy for treatment of hyperglycemia and involves administering premeal insulin 4-6 times per day, depending on the pre-meal blood glucose.

Although it has been frequently used, there is a lack of evidence supporting the effectiveness of this practice. ${ }^{4}$ Sliding-scale insulin usually consists of regular insulin or rapid-acting insulin given alone. This technique has been shown to be ineffective for the following reasons: the reactive approach can lead to rapid swings in blood glucose, resulting in hyperglycemia and hypoglycemia, the regimen in place at admission is likely to be used throughout the hospitalization without appropriate change or titration, and hyperglycemia is treated after the fact instead of proactively anticipating need. In a retrospective study, Freedman et $\mathrm{al}^{5}$ proposed that patients with high admission blood glucoses were more likely to be placed on a sliding scale insulin (SSI) protocol. Freedman also indicated that other patients were often placed on a sliding scale protocol because it was a method that was passed down from trainee to trainee as an easy, "auto-pilot" way to treat diabetes in the hospital, a method that would limit the 
need for physician intervention. The hazards of sliding-scale insulin use exceed the advantages of its convenience, and thus prolonged therapy using this insulin as the sole source of treatment is discouraged. ${ }^{6}$

In the noncritical care setting, scheduled subcutaneous insulin that delivers basal, nutritional (bolus), and correction (supplemental) doses are preferred because this type of therapy is shown to be more physiological-ie, more closely matching endogenous basal and bolus insulin secretion. ${ }^{3}$ However, SSI is still predominantly used on the study hospitals' medical non-critical care units. Insulin protocols at this hospital are prescribed by hospitalists, residents, surgeons, internal medicine physicians, family medicine physicians, and nurse practitioners (NPs)/physician assistants. The orders are implemented by the staff nurses and are often a source of frustration as they are usually the first caregiver to recognize that the blood glucose is not being well-controlled.

Diabetes NPs can be consulted to collaborate with staff nurses on a regimen change and patient education needs. Diabetes NPs can implement best practices as they relate to control of inpatient hyperglycemia and are key providers to coordinate and provide inpatient diabetes care.

\section{Methods}

A retrospective chart review of patients hospitalized with known type 2 diabetes was conducted for the purpose of quality improvement at a 140-bed, central-city teaching hospital in Milwaukee, WI. The chart review was specifically performed to study the outcomes that basal bolus vs SSI protocols had on fasting, mean, and discharge blood glucoses, length of stay (LOS), and episodes of mild/moderate or severe hypoglycemia. Inclusion criteria included patients age 18-80, admitted to general medical units, and managed on either basal/bolus or SSI protocols.

Exclusion criteria included patients admitted to critical care units, including intermediate care units, as well as surgical and obstetrical units. Patients who were found to have undergone surgery, though admitted initially to a medical unit, were excluded, as well as those who received steroids, oral diabetes agents, or intravenous insulin at any time during their stay. Patients who were hospitalized for fewer than 3 days were also excluded.

The institutional review boards at the study hospital and Marquette University approved the quality improvement study. Clinical information services at the study hospital conducted a search using ICD 9 diagnosis codes of 250.0 and 250.02 and the aforementioned inclusion and exclusion criteria for patients admitted between January 1, 2009, and January 1, 2012. Lists were provided by clinical information services that identified patients by their medical record number, discharge date, LOS, age, sex, ethnicity, admission diagnosis, and nursing unit.

A review of the electronic record for each patient who met the inclusion criteria was conducted in the sequence in which they appeared. Subjects were de-identified. The blood glucose data included glucose levels tested before each meal and at bedtime. The goal of insulin therapy was to maintain fasting and pre-meal blood sugars $<140 \mathrm{mg} / \mathrm{dl}(7.78 \mathrm{mmol} / \mathrm{l})$, and overall $<180 \mathrm{mg} / \mathrm{dl}(10.0 \mathrm{mmol} / \mathrm{l})$ while avoiding hypoglycemia (no lower than $70 \mathrm{mg} / \mathrm{dl}$ or $3.89 \mathrm{mmol} / \mathrm{l}$ ). ${ }^{3}$ The primary goal was to determine differences between the 2 groups of subjects based on the type of insulin protocol. 


\section{Sample}

A power analysis was conducted using the G*Power calculator (Buchner, Erdfelder, and Faul, Duesseldorf Germany) for an independent $t$-test. It was concluded that to achieve significance, a sample of 128 patients with type 2 diabetes was required. The sample size was evenly divided between patients placed on basal/bolus protocols and those placed on SSI protocols. The demographic variable data collected for the sample included age, ethnicity, sex, admission blood glucose, admission diagnosis, hemoglobin A1C, serum hemoglobin, serum creatinine, and white blood cell count. These particular variables were chosen because they can have an impact on the blood glucose and help explain hyper and hypoglycemia.

The independent $t$-test was used for variables with continuous data, and the Mann Whitney $U$ test was used for variables with categorical data. The age of the sample did not differ significantly: sliding-scale group (SS) age mean = 65.2 \pm standard deviation = 9.6; basal-bolus group (BB) age $63.3 \pm 11.8$. Ethnicity of the sample revealed largely an African American population for both groups because of the hospital location, with smaller populations of white and Hispanic patients.

The sex of the sample did not differ on the large number of women vs men. The admission glucoses were similar (SS $210.3 \pm 149.5$; BB $210.3 \pm 138.2$ ), and hemoglobin A1c values did not differ as both groups were admitted in fairly poor control (SS $8.3 \pm 1.6$; BB $8.2 \pm 2.03$ ). The white cell count did not reveal a large mean for infections being a major reason for admissions (SS $8.5 \pm 3.3 ; \mathrm{BB} 9.2 \pm 4.2$ ), and hemoglobin values did not indicate that anemia was significantly low, leading to an inaccurate Hemoglobin A1c value (SS $10.9 \pm 2.3$; BB $11.5 \pm 2.8$ )

Finally, though the creatinine value of the groups did not show a statistically significant difference $(P=$ .395), the means indicated that a large portion of the SS group had high creatinines as compared to the BB group (SS $2.9 \pm 3.3$; BB $1.7 \pm 1.6$ ). This may be an interesting future study as another reason for the safety of using a BB regimen (Table 1 ).

Table 1. Description of Sample/Demographic Variables

\begin{tabular}{|l|l|l|l|}
\hline Variable & $\begin{array}{l}\text { Sliding Scale Protocol } \\
\text { Mean \& SD (n = 64) }\end{array}$ & $\begin{array}{l}\text { Basal Bolus Protocol } \\
\text { Mean \& SD (n = 64) }\end{array}$ & $\begin{array}{l}\text { P value: Ind. } \text { - } \\
\text { test/MannWhitney U }\end{array}$ \\
\hline Age (years) & $65.2 \pm 9.6$ & $63.3 \pm 11.8$ & .273 \\
\hline Ethnicity & $59 \mathrm{AA}, 2 \mathrm{~W}, 3 \mathrm{H}$ & $53 \mathrm{AA}, 6 \mathrm{~W}, 5 \mathrm{H}$ & .244 \\
\hline $\begin{array}{l}\text { Sex } \\
\text { (female/male) }\end{array}$ & $40 \mathrm{~F}, 24 \mathrm{M}$ & $38 \mathrm{~F}, 26 \mathrm{M}$ & .333 \\
\hline $\begin{array}{l}\text { Admission } \\
\text { glucose }\end{array}$ & $210.3 \pm 149.5$ & $210.3 \pm 138.2$ & .774 \\
\hline $\begin{array}{l}\text { Hemoglobin A1C } \\
\text { (\%) }\end{array}$ & $8.3 \pm 1.6$ & $8.2 \pm 2.03$ & .860 \\
\hline $\begin{array}{l}\text { White blood cell } \\
\text { count }\end{array}$ & $8.5 \pm 3.3$ & $9.2 \pm 4.2$ & .190 \\
\hline Hemoglobin & $10.9 \pm 2.3$ & $11.5 \pm 2.8$ & .526 \\
\hline Creatinine & $2.9 \pm 3.3$ & $1.7 \pm 1.6$ & .395 \\
\hline
\end{tabular}

$\mathrm{AA}=$ African American; $\mathrm{W}=$ white; $\mathrm{H}=$ Hispanic. 
$\mathrm{P}=<0.05$.

Statistical Analysis

Statistical analysis was performed using the SPSS software package (IBM Corporation, Armonk, NY). ${ }^{7}$ Independent $t$-tests were used to analyze continuous variables. Distributions on scores of several dependent variables were not normally distributed, and thus equality of variances was not assumed. Because of the possibility of a $30 \%$ type 1 error with multiple $t$ tests, the confidence interval was set at $70 \%$.

\section{Results}

The means and standard deviations for variables associated with the hypotheses are reported in Table 2 where the $P$ value demonstrated those variables that showed significance. The first hypothesis (H1) was that there would be a significant difference between BB and SSI protocols on fasting blood glucose, mean blood glucose, and discharge blood glucose. This hypothesis was supported with fasting blood glucose values: SS 201.4 \pm 33.7 ; BB $135.5 \pm 29.9$, mean blood glucose values: SS $225 \pm 37.5$; BB $149 \pm 23.1$, and discharge blood glucose values: SS $244.3 \pm 68.2$; BB $128.6 \pm 27.3$ (Table 2).

Table 2. Results

\begin{tabular}{|c|c|c|c|c|c|c|c|}
\hline Variables & $\begin{array}{l}\text { Sliding } \\
\text { Scale } \\
\text { Protocol } \\
\text { Mean \& SD } \\
(n=64)\end{array}$ & $\begin{array}{l}\text { Basal Bolus } \\
\text { Protocol } \\
\text { Mean \& SD } \\
(n=64)\end{array}$ & $\begin{array}{l}\text { Sig. (2- } \\
\text { tailed) }\end{array}$ & $t$ & $\begin{array}{l}\text { Std. Error } \\
\text { Difference }\end{array}$ & $\begin{array}{l}70 \% \\
\text { Confidence } \\
\text { Interval }\end{array}$ & \\
\hline & & & & & & Lower & Upper \\
\hline $\begin{array}{l}\text { Fasting } \\
\text { blood } \\
\text { glucose }\end{array}$ & $\begin{array}{l}201.4 \pm \\
33.7\end{array}$ & $\begin{array}{l}135.5 \pm \\
29.9\end{array}$ & .000 & 11.711 & 5.62633 & 60.03521 & 71.74604 \\
\hline $\begin{array}{l}\text { Mean } \\
\text { blood } \\
\text { glucose } \\
\end{array}$ & $225 \pm 37.5$ & $149 \pm 23.1$ & .000 & 13.813 & 5.50101 & 70.25461 & 81.71414 \\
\hline $\begin{array}{l}\text { Discharge } \\
\text { blood } \\
\text { glucose }\end{array}$ & $\begin{array}{l}244.3 \pm \\
68.2\end{array}$ & $\begin{array}{l}128.6 \pm \\
27.3\end{array}$ & .000 & 12.610 & 9.17937 & 106.17619 & 125.32381 \\
\hline $\begin{array}{l}\text { Mild/mod. } \\
\text { hypo }\end{array}$ & $\begin{array}{l}.6250 \pm \\
1.29\end{array}$ & $.7031 \pm 1.3$ & .730 & -.345 & .22623 & -.31357 & .15732 \\
\hline $\begin{array}{l}\text { Severe } \\
\text { hypo }\end{array}$ & $.1719 \pm .46$ & $.1406 \pm .59$ & .737 & .336 & .09296 & -.06550 & .12800 \\
\hline $\begin{array}{l}\text { Length of } \\
\text { stay (days) }\end{array}$ & $4.6 \pm 1.9$ & $4.8 \pm 2.8$ & .195 & -.473 & .42950 & -.65012 & .24387 \\
\hline
\end{tabular}

The second hypothesis ( $\mathbf{H 2}$ ) was that there would be a significant difference in length of stay for BB and SSI protocols. This hypothesis was not supported as values included: SS $4.6 \pm 1.9 ; \mathrm{BB} 4.8 \pm 2.8$ (Table 2). 
The third hypothesis (H3) was that there would be a significant difference in the incidence of mild/moderate and severe hypoglycemic episodes for BB and SSI protocols. This hypothesis was not supported with values for mild/moderate hypoglycemia (SS .6250 \pm 1.29 ; BB .7031 \pm 1.3 ) and for

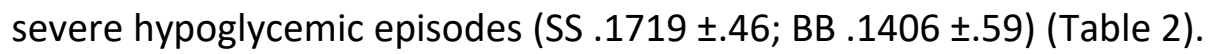

\section{Discussion}

Overall, this study was consistent with other research on BB regimens as far as improvements seen in fasting blood glucose, mean blood glucose, and discharge blood glucose. 2, 5, 8, 9, 10, 13, 14 The results for $\mathbf{H 1}$ are consistent with Freedman et $\mathrm{al}^{5}$, in which patients on SSI had a mean blood glucose $>270 \mathrm{mg} / \mathrm{dl}$ $(15.0 \mathrm{mmol} / \mathrm{l})$. The mean blood glucose in this study for patients on the SSI protocol was $224 \mathrm{mg} / \mathrm{dl}$ (12.4 mmol/I). In Umpierrez et $\mathrm{al}^{11}$, the mean for SSprotocol patients was $193 \mathrm{mg} / \mathrm{dl}(10.7 \mathrm{mmol} / \mathrm{l})$, and the mean fasting blood glucose was $165 \mathrm{mg} / \mathrm{dl}(9.17 \mathrm{mmol} / \mathrm{l})$. The fasting blood glucose in this study for SS protocol patients was $201 \mathrm{mg} / \mathrm{dl}(11.17 \mathrm{mmol} / \mathrm{l})$. These results are all higher than the pre-meal glucose target of $<140 \mathrm{mg} / \mathrm{dl}(7.78 \mathrm{mmol} / \mathrm{l})$ and random glucose target of $<180 \mathrm{mg} / \mathrm{dl}(10.0 \mathrm{mmol} / \mathrm{l})$ as set by the American Diabetes Association, suggesting that SSI protocols do not meet the standards for achieving good glycemic control in this study. ${ }^{3}$

The analysis of hypoglycemia revealed that there were no statistically significant results regarding episodes of mild/moderate (< $70 \mathrm{mg} / \mathrm{dl}$ or $3.9 \mathrm{mmol} / \mathrm{l}$ ) or severe hypoglycemia $(<50 \mathrm{mg} / \mathrm{dl}$ or 2.8 $\mathrm{mmol} / \mathrm{I})$. There were a slightly larger number of episodes of mild/moderate hypoglycemia with BB therapy than with SS therapy and slightly more episodes of severe hypoglycemia with SS therapy as compared to BB therapy. This is consistent with other studies as far as SS being a potentially dangerous therapy as compared to BB therapy. $5,10,15$

The analysis of the LOS data was also not statistically significant between BB and SS groups. The mean LOS were similar for both groups, and compared to Umpierrez et $\mathrm{al}^{11}$, this study actually had shorter LOS.

The analysis of the other variables concluded that there were no statistically significant differences in age, ethnicity, sex, white blood cell count, hemoglobin, creatinine, A1C, or admission blood glucose for either group.

The knowledge and expertise in diabetes of the advanced practice nurse, along with a specialty flowsheet within the electronic medical record, provided consistency and reliability in how the data were collected. Finally, the sample consisted of patients from medical units with a prior diagnosis of type 2 diabetes, so this was a fairly homogeneous convenience sample from 1 hospital.

\section{Limitations}

One limitation of this study included its retrospective design. The retrospective electronic medical record does not allow the researcher to inquire why decisions were made. For example, glucose readings may have been taken shortly after the patient had begun eating and the insulin dose may not have been timed appropriately with meals. This hospital allowed "on-demand meals," and thus patients could order meals when they wanted and would receive and start eating the meal without the staff RN's knowledge. The meal-time insulin would then be given late. Since this study was done, a 
system was put into place whereby a sign on the door alerted the kitchen staff to contact the patient's RN before giving the patient a tray.

Generalizability of the results was limited because of the sample being from noncritical care units and because the sample was obtained from a single central-city hospital. Thus, though the study is replicable, it may not be representative of diabetes care in other settings.

Another limitation of this study is that it did not track how many patients were admitted because they had infections compared to how many were admitted only for poorly controlled diabetes.

\section{Conclusion}

The results of this project provide direction for improving the care of hospitalized patients with hyperglycemia in this facility. The evidence that BB insulin protocols provide improved glycemic control over SS protocols in this facility needs to be presented to all caregivers.

NPs specializing in diabetes are key members of the inpatient care team for the translation of research related to evidence-based diabetes practice. In addition to providing this evidence, NPs specializing in diabetes should be included on committees that write institutional guidelines on when and how to initiate and change/adjust insulin therapy. This topic should be part of every orientation for 1st year residents and part of the yearly competency skills for RNs.

Protocols via the electronic medical record should also be designed to allow staff nurses to implement interventions independently such as basal/bolus dos-ing based on a patient's weight. Inpatient diabetes update sessions would also benefit other prescribers such as hospitalists and external providers who still admit their own patients. The advanced practice diabetes educator can be instrumental in coordinating future studies to assess progress with the use evidence-based practice diabetes protocols, as well as studies that assess the rate of 30-day readmissions for uncontrolled hyperglycemia since this is now being scrutinized regarding reimbursement. ${ }^{12}$

\section{References}

1 A. Frisch, P. Chandra, D. Smiley, et al. Prevalence and clinical outcome of hyperglycemia in the perioperative period in non-cardiac surgery. Diabetes Care, 33 (8) (2010), pp. 1783-1788

2 C. Cook, J. Castro, R. Schmidt. Diabetes care in hospitalized non-critically ill patients: more evidence for clinical inertia and negative therapeutic momentum. Soc Hospital Med, 2 (4) (2007), pp. 203-211

3 American Diabetes Association. Clinical Practice Recommendations-Executive summary: Standards of medical care in diabetes. Diabetes Care, 34 (Suppl. 1) (2011), pp. S9-S10

4 L. Golightly, M. Jones, D. Hamamura, N. Stolpman, M. McDermott. Management of diabetes mellitus in hospitalized patients: efficiency and effectiveness of sliding-scale insulin therapy. Pharmacotherapy, 26 (10) (2006), pp. 1421-1432

5 R. Freedman, S. Samson, A. Edwards. Glycemic control and use of the insulin sliding scale in hospitalized patients with diabetes. J Healthcare Quality, 29 (2) (2007), pp. 31-37

6 E.S. Moghissi, M.T. Korytkowski, M. DiNardo, et al. American Association of Clinical Endocrinologists and American Diabetes Association consensus statement on inpatient glycemic control. Diabetes Care, 32 (6) (2009), pp. 1119-1131

7 A. Field. Discovering statistics using SPSS. (3rd ed.), Sage Publications, London (2009) 
8 A. Ahmann. Reduction of hospital costs and lengths of stay by good control of blood glucose levels. Endocrine Practice, 10 (Suppl. 2) (2004), pp. 53-56

9 T. Becker, A. Moldoveanu, T. Cukierman, H. Gerstein. Clinical outcomes associated with the use of subcutaneous insulin-by-glucose sliding scales to manage hyperglycemia in hospitalized patients with pneumonia. Diabetes Res Clin Pract, 78 (2007), pp. 392-397

10 S. Braithwaite, M. Buie, C. Thompson. Hospital hypoglycemia: not only treatment, but also prevention. Endocrine Practice, 10 (Suppl. 2) (2004), pp. 89-99

11 G.E. Umpierrez, D. Smiley, A. Zisman. Randomized study of basal-bolus insulin therapy in the inpatient management of patients with type 2 diabetes (RABBIT 2 Trial). Diabetes Care, 30 (9) (2007), pp. 2182-2186

12 M.D. Silverstein, H. Qin, S.Q. Mercer, J. Fong, Z. Haydar. Risk factors for 30-day hospital readmission in patients $\geq 65$ years of age. Baylor University Medical Center Proceedings, 21 (4) (2008), pp. 363-372

13 A. Furnary, G. Grunkemeier, W. Zerr, S. Bookin, H. Floten, A. Starr. Continuous insulin infusion reduces mortality in patients with diabetes undergoing coronary artery bypass grafting. J Thoracic Cardiovasc Surg, 125 (2003), pp. 1007-1021

$14 \mathrm{~V}$. Magaji, J. Johnston. Inpatient management of hyperglycemia and diabetes. Clin Diabetes, 29 (1) (2011), pp. 3-9

15 D. Smiley, G. Umpierrez. Management of hyperglycemia in hospitalized patients. Ann New York Acad Sci, 1212 (2010), pp. 1-11

Heidi L Rymaszewski, DNP, ANP-BC, BC-ADM, CDE, is an adult nurse practitioner with the Aurora Medical Group-Diabetes and Nutrition Education Dept. in Milwaukee, WI

Susan Breakwell, APHN-BC, DNP, is a clinical associate professor at Marquette University in Milwaukee, WI.

In compliance with national ethical guidelines, the authors report no relationships with business or industry that would pose a conflict of interest. 